\title{
Herbal antihyperlipidemic formulation of cocoa tea: Preparation and in vivo comparison with atorvastatin
}

\author{
Jing Li, Yi-QiangYuan, Rui-Min Wang, Li Yu, Li Zhang, Yu-Jie Zhao, Hua \\ Zhang, Jia-Jian Dong and Jin-Ying Zhang* \\ Department of Cardiology, Zhengzhou Cardiovascular Hospital, Zhengzhou, Henan 450016, PR China
}

*For correspondence: Email: zhangjinying@hotmail.com; Tel/Fax: 0086-371-67967642

Received: 1 August 2016

Revised accepted: 18 November 2016

\begin{abstract}
Purpose: To prepare and characterize a formulation containing an ethanol extract of Camellia ptilophylla leaves (cocoa tea), with a focus on antihyperlipidemic and anti-obesity activities.

Methods: An aloe vera-based formulation of an ethanol extract of cocoa tea (C. ptilophylla) was prepared. The formulation was given orally at $400 \mathrm{mg} / \mathrm{kg}$ daily to obese (high-fat diet-induced) mice for 1 month, and body weight as well as total cholesterol, triglyceride, HDL cholesterol, LDL cholesterol, and VLDL cholesterol levels were determined and compared with those of control and standard groups (the latter mice received atorvastatin at $400 \mathrm{mg} / \mathrm{kg}$ daily).

Results: At the end of treatment, the standard group exhibited $64.65 \%$ reduction in body weight gain and the test group exhibited $48.87 \%$ reduction, compared with control. The group that received the formulation had significantly lower levels of serum total cholesterol, triglycerides, and LDL cholesterol, and a higher level of HDL cholesterol.

Conclusion: The formulation of an ethanolic extract of cocoa tea leaves seems to exert antihyperlipidemic and anti-obesity activities comparable to those of a modern lipid-lowering agent (atorvastatin) in mice. Thus, this natural remedy has the potential to prevent or delay hyperlipidemia and the cardiovascular complications associated with diet-induced obesity.
\end{abstract}

Keywords: Obesity, Lipid profile, Cocoa tea (Camellia ptilophylla) leaves, Weight management, Herbal formulation, Antihyperlipidemic, Anti-obesity

Tropical Journal of Pharmaceutical Research is indexed by Science Citation Index (SciSearch), Scopus, International Pharmaceutical Abstract, Chemical Abstracts, Embase, Index Copernicus, EBSCO, African Index Medicus, JournalSeek, Journal Citation Reports/Science Edition, Directory of Open Access Journals (DOAJ), African Journal Online, Bioline International, Open-J-Gate and Pharmacy Abstracts

\section{INTRODUCTION}

Obesity is one of the most common global health problems. The condition is associated with abnormal levels of blood lipids (hyperlipidemia) and lipoproteins (hyperlipoproteinemia). Hyperlipidemia comprises a heterogeneous group of disorders, characterized by high blood levels of one or more lipids and/or lipoproteins [atherogenic free fatty acids, triglycerides (TGs; hypertriglyceridemia), small dense low-density lipoprotein cholesterol (LDL-C; hypercholesterolemia), and apolipoprotein B] and/or low levels of anti-atherogenic high- density lipoprotein cholesterol (HDL-C) [1]. According to the American Association of Clinical Endocrinologists and the International Diabetes Federation, metabolic syndrome can be defined as a group of complex symptoms featuring central obesity (waist circumference $>102 \mathrm{~cm}$ in males and $>88 \mathrm{~cm}$ in females) and two or more of the following: elevated serum level of TGs, elevated serum level of glucose (hyperglycemia), elevated blood pressure, and reduced serum level of HDLassociated cholesterol [2]. 
Obese individuals are at high risk for the development or worsening of cardiovascular disorders and diabetes [2]. Therefore, dietary supplements containing antioxidants and hypolipidemic agents may be useful to prevent and manage obesity and related complications $[3,4]$. Weight-loss drugs are frequently associated with one or more side effects, which are sometimes very harmful. Herbal drugs and products used in traditional Chinese medicine (TCM) have been reported to control and manage hyperlipidemia and weight [5]. Over the last few decades, hundreds of Chinese herbal medicines and other herbal products of various forms have been reported to be excellent alternatives when used to develop safer and more effective anti-obesity drugs. More than 50 TCM formulae (patented drugs) approved by the China Food and Drug Administration are used to treat hyperlipidemia [6]. Cocoa tea (Camellia ptilophylla) is a natural (caffeine-free) plant used for centuries by inhabitants of the Longmen area of Guangdong Province, China. Research on the therapeutic effects of the plant commenced in the 1980s [7,8]. Various studies have found that cocoa tea exerts profound cytotoxic effects on various cancer cell lines and significantly reduces plasma TG levels in hyperlipidemic mice $[9,10]$.

Lipid profile management is one of the most successful strategies for the management of obesity [11]. The present investigation involved the preparation and evaluation of a formulation of an ethanolic extract of cocoa tea leaves, with a focus on antihyperlipidemic and anti-obesity activities.

\section{EXPERIMENTAL}

\section{Materials}

Cocoa tea leaves were collected from the Guangdong Academy of Agricultural Sciences, China. All other ingredients used were of analytical grade.

\section{Preparation and formulation of an ethanol leaf extract of cocoa tea}

Leaves were dried in the shade, coarsely powdered, extracted with n-hexane, and dried for 5 days in the shade at room temperature. The dried residue was immersed in ethanol for 10 days and an ethanol extract was obtained by evaporating off the ethanol in a rotary vacuum evaporator (an ice-trap model). The extract was vacuum dried and stored in a desiccator. The yield was $75.89 \%$ of the original weight of the leaves. The extract was dissolved to $20 \% \mathrm{w} / \mathrm{w}$, with continuous stirring, in the juice of leaves of aloe vera. This juice was prepared from the pulp of fresh leaves by making longitudinal incisions in the mid-surfaces of leaves and then collecting the pulp, to which ascorbic acid $(0.5 \% \mathrm{w} / \mathrm{v})$ was added as a stabilizer, with continuous stirring. The formulation thus obtained was the antihyperlipidemic preparation.

\section{In vivo assessment of antihyperlipidemic and anti-obesity activities}

Healthy young Swiss albino mice weighing 75 $105 \mathrm{~g}$ were used. The study protocols were approved by the Animal Experimentation Ethics Committee, Zhengzhou Cardiovascular Hospital, Zhengzhou (approval no. 2014/193). Mice were kept in individual polypropylene cages with food and water provided ad libitum at $22 \pm 2{ }^{\circ} \mathrm{C}$ and a relative humidity of $50 \pm 15 \%$, under a 12/12-h light/dark cycle. The animals were handled as recommended by the Guidelines of the European Commission [12].

The mice were divided into four groups of six animals each and acclimatized for 1 week prior to dosing. Group I (normal control) consumed a normal chow diet containing $6 \% \mathrm{w} / \mathrm{w}$ fat (diet SF04-057; Specialty Foods, Glen Forest, Western Australia). Hyperlipidemia was induced in all other groups by feeding a high-fat diet (HFD) containing $21 \% \mathrm{w} / \mathrm{w}$ butterfat and $0.15 \%$ cholesterol (diet SF00-219; Specialty Foods) for 1 month before the study. The mice were dosed as follows. Group I (normal control) mice continued on a normal diet. The other groups continued on the HFD. Group II (obese control) mice received no treatment. Group III (standard group) received daily atorvastatin $(40 \mathrm{mg} / \mathrm{kg}$, orally). Group IV (test group) received the test formulation daily (400 mg/kg, orally).

Four weeks later, blood was collected by cardiac puncture and various biochemical tests were performed [11]. Blood was collected into heparincontaining tubes and plasma was separated by centrifugation $(3,000 \mathrm{rpm}, 10 \mathrm{~min})$. Lipid levels were measured immediately or the plasma was frozen $\left(-80^{\circ} \mathrm{C}\right)$ for future use. We measured the levels of total cholesterol (TC), TGs, HDL-C, creatinine, potassium, LDL-C, and very-lowdensity-lipoprotein cholesterol (VLDL-C) using the following formulae: LDL-C = TC $-\mathrm{HDL}-\mathrm{C}-$ $(\mathrm{TGs} / 5)$ and VLDL-C $=\mathrm{TGs} / 5$.

\section{Statistical analysis}

Results are expressed as means \pm standard deviations. Statistical analysis was performed 
using one-way analysis of variance with GraphPad Prism( 94.0 software. $P<0.05$ was considered to reflect significance.

\section{RESULTS}

Cocoa tea leaf extract was prepared by cold infusion, followed by vacuum evaporation of ethanol at reduced pressure and low temperature. The formulation was given orally to obese mice for 4 weeks. Cocoa tea leaves have been used traditionally to prepare beverages and in TCM in China. We explored the anti-obesity and antihyperlipidemic activities of an aloe verabased formulation of an ethanolic extract of cocoa tea leaves in HFD-induced obese and hyperlipidemic mice.

Body weight increased in the HFD group from $94.09 \pm 3.44$ to $112.09 \pm 2.04 \mathrm{~g}$, and in the standard group from $97.09 \pm 1.44 \mathrm{~g}$ to $107.06 \pm$ $1.02 \mathrm{~g}$. Body weight increased in mice receiving the formulation from $96.08 \pm 1.02 \mathrm{~g}$ to only $108.01 \pm 2.54 \mathrm{~g}$. At the end of treatment, the standard group exhibited a $64.65 \%$ reduction in body weight gain, and the test group exhibited a $48.87 \%$ reduction (by reference to the control), compared with the HFD group (Table 1).
It was found that the total lipid profile of the HFD group was significantly higher than that of the normal control, and those of the HFD + Std. and HFD + Test groups were similar to that of the normal control. The HFD-induced abnormal lipid profile was improved by the herbal formulation. The formulation lowered serum TC, TG, and LDL-C levels compared with the HFD groups, as did the standard drug (Figure 1).

At the end of treatment, the TC concentrations were significantly lower in the HFD + Std. (84.88 $\pm 1.24 \mathrm{mg} / \mathrm{dL})$ and HFD + Test (90.34 \pm 1.01 $\mathrm{mg} / \mathrm{dL}$ ) groups compared with the HFD group $(201.14 \pm 0.09 \mathrm{mg} / \mathrm{dL})$. The TG levels were also significantly lower in the HFD + Std. $(67.31 \pm$ $1.02 \mathrm{mg} / \mathrm{dL})$ and HFD + Test $(72.66 \pm 1.10$ $\mathrm{mg} / \mathrm{dL}$ ) groups compared with the HFD group $(159.4 \pm 0.21 \mathrm{mg} / \mathrm{dL})$. The HDL-C concentrations were significantly higher in the HFD + Std. (18.84 $\pm 0.22 \mathrm{mg} / \mathrm{dL})$ and HFD + Test (16.98 \pm 0.12 $\mathrm{mg} / \mathrm{dL})$ groups than in the HFD group $(10.98 \pm$ $0.38 \mathrm{mg} / \mathrm{dL}$ ). The LDL-C concentrations were significantly lower in the HFD + Std. (52.57 \pm $1.84 \mathrm{mg} / \mathrm{dL})$ and HFD + Test (58.83 \pm 1.49 $\mathrm{mg} / \mathrm{dL}$ ) groups than in the HFD group (158.28 \pm $2.44 \mathrm{mg} / \mathrm{dL}$; Table 2).

Table 1: Effect of a formulation of cocoa tea leaf extract on the body weights of obese mice consuming a high-fat diet

\begin{tabular}{lcccc}
\hline Body weight & \multicolumn{3}{c}{ Body weight (g) } & \multicolumn{3}{c}{ HFD + Std $^{\mathrm{a}}$} \\
\cline { 2 - 5 } & Normal $^{\mathrm{a}}$ & HFD $^{\mathrm{a}}$ & HFD + Test $^{\mathrm{a}}$ & $97.09 \pm 1.44$ \\
Initial $(\mathrm{g})$ & $90.00 \pm 2.09$ & $94.09 \pm 3.44$ & $96.08 \pm 1.02$ & $107.06 \pm 1.02^{\mathrm{b}}$ \\
Final (g) & $95.58 \pm 1.11$ & $112.09 \pm 2.04^{\mathrm{b}}$ & $108.01 \pm 2.54^{\mathrm{b}}$ & $9.97 \pm 1.42^{\mathrm{b}}$ \\
Body weight gain (g) & $5.58 \pm 1.08$ & $18.00 \pm 2.1^{\mathrm{b}}$ & $11.93 \pm 1.24^{\mathrm{b}}$ & $-4.39(-64.65 \%)$ \\
Increase in body weight vs. & & $+12.42(100 \%)$ & $-6.35(-48.87 \%)$ & \\
control $( \pm \mathrm{g})(\%)^{*}$ & & & &
\end{tabular}

*The increase in body weight gain in the HFD group was taken as $100 \%$ and other gains were calculated by comparison); ${ }^{a}$ mean \pm SD $(n=6) ;{ }^{b} p<0.05$

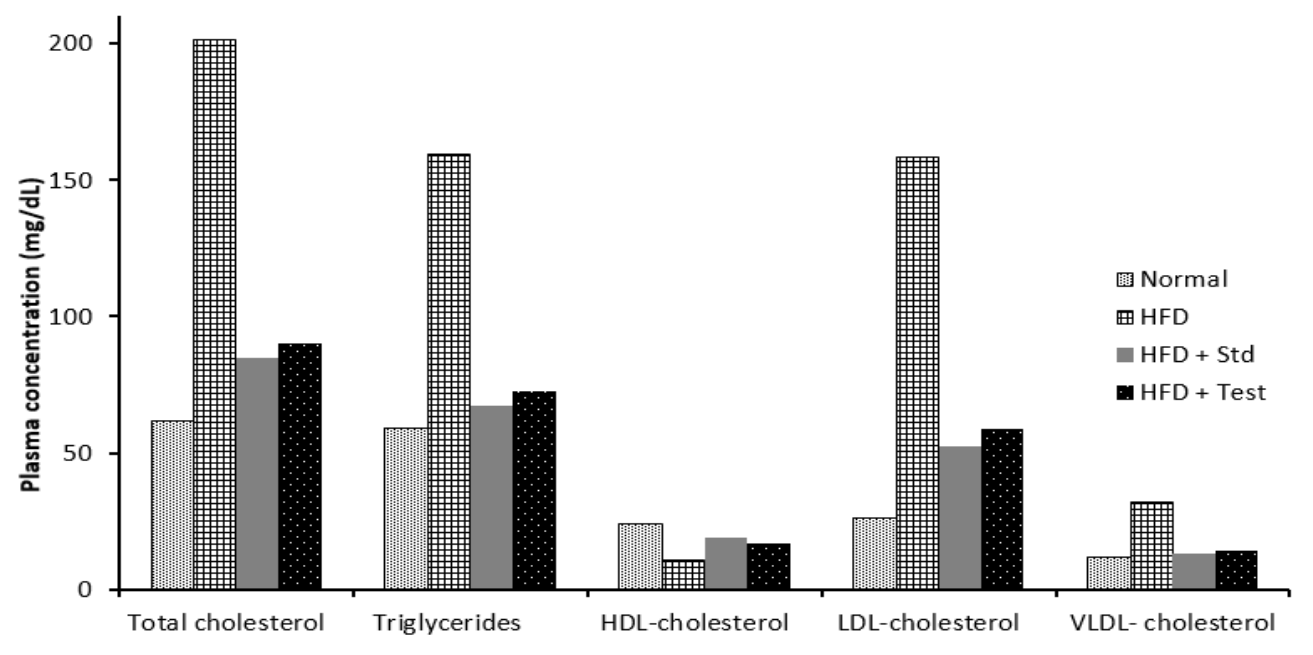

Figure 1: Lipid profile of mice with diet-induced obesity 
Table 2: Plasma lipid profiles induced by the cocoa tea leaf formulation

\begin{tabular}{|c|c|c|c|c|c|c|}
\hline \multirow[b]{2}{*}{ Group } & \multicolumn{6}{|c|}{ Plasma concentration (mg/dL) ${ }^{a}$} \\
\hline & $\begin{array}{l}\text { Total } \\
\text { cholesterol }\end{array}$ & $\begin{array}{l}\text { Triglyceride } \\
\mathrm{s}\end{array}$ & $\begin{array}{l}\text { HDL } \\
\text { cholesterol }\end{array}$ & $\begin{array}{l}\text { LDL } \\
\text { cholesterol }\end{array}$ & $\begin{array}{l}c L D L \\
\text { cholesterol }\end{array}$ & $\begin{array}{l}H D L / L D L \\
\text { ratio }\end{array}$ \\
\hline Normal & $62.0 \pm 1.02$ & $59.0 \pm 0.14$ & $24.12 \pm 0.01$ & $26.08 \pm 0.29$ & $11.8 \pm 0.01$ & $0.93 \pm 0.01$ \\
\hline HFD & $201.14 \pm 0.09$ & $159.4 \pm 0.21$ & $10.98 \pm 0.38^{b}$ & $158.28 \pm 2.44^{\mathrm{b}}$ & $31.88 \pm 1.11^{\mathrm{b}}$ & $0.07 \pm 0.12^{b}$ \\
\hline HFD + Std & $84.88 \pm 1.24$ & $67.31 \pm 1.02^{\mathrm{b}}$ & $18.84 \pm 0.22^{\mathrm{b}}$ & $52.57 \pm 1.84^{\mathrm{b}}$ & $13.46 \pm 1.24^{\mathrm{b}}$ & $0.36 \pm 0.04^{b}$ \\
\hline HFD + Test & $90.34 \pm 1.01$ & $72.66 \pm 1.10^{\mathrm{b}}$ & $16.98 \pm 0.12^{\mathrm{b}}$ & $58.83 \pm 1.49^{\mathrm{b}}$ & $14.53 \pm 0.08^{\mathrm{b}}$ & $0.29 \pm 0.08^{\mathrm{b}}$ \\
\hline
\end{tabular}

HDL/LDL ratio was significantly higher in the HFD + Std. $(0.36 \pm 0.04)$ and HFD + Test $(0.71 \pm$ $0.21)$ groups in comparison of HFD group $(0.29 \pm$ 0.08). Thus, the test formulation showed good HDL/LDL ratio similar to that of standard

\section{DISCUSSION}

Various studies have found that high-level motivation toward implementing changes in diet and lifestyle may not be adequate for body weight management in more than $80 \%$ of obese subjects [13,14]. Therefore, specific drugs are necessary. Despite much research effort, only a few such drugs are available, and they are associated with adverse effects. The United States Food and Drug Administration has approved certain anti-obesity drugs, but they are associated with high incidences of cardiovascular and depressive effects. Some such drugs have been withdrawn from the market [15]. Because of these side effects, natural products are being explored as safer alternatives. Crude herbal extracts and isolated phytoconstituents can induce body weight reduction and prevent dietinduced obesity [16].

Our new formulation (and atorvastatin) improved the lipid profile by lowering serum TC, TG, and LD-C levels compared with the HFD group. Various preclinical human studies have confirmed the anti-obesity effects of green tea extracts [17-19]. The beneficial effects of green and cocoa teas have been attributed to catechins, particularly epigallocatechin gallate (EGCG) [20-23]. Various studies have found that cocoa tea supplementation dose-dependently downregulated the expression levels of genes controlling cholesterol uptake (LDL-R) and cholesterol synthesis (HMG Co-A reductase), and exhibited strong antioxidant activities [2325].

We conclude that our new formulation improves the HDL/LDL ratio, restoring it to the normal range. Improved HDL levels contribute to the prevention of adiposity. However, further studies are required to compare the activities of the formulation to those of other weight-management preparations.

\section{CONCLUSION}

Short-term treatment with cocoa tea formulation effectively reduced the levels of TC, TGs and LDL-C, but improved HDL/LDL ratio in dietinduced obese mice. Thus, the formulation may serve as a potential antihyperlipidemic and antiobesity agent for the treatment of diet-induced hyperlipidemia and obesity in man.

\section{DECLARATIONS}

\section{Acknowledgement}

The authors thank Zhengzhou Cardiovascular Hospital, Zhengzhou, for making available the required facilities for this study.

\section{Conflict of Interest}

No conflict of interest associated with this work.

\section{Contribution of Authors}

The authors declare that this work was done by the authors named in this article and all liabilities pertaining to claims relating to the content of this article will be borne by them.

\section{Open Access}

This is an Open Access article that uses a funding model which does not charge readers or their institutions for access and distributed under the terms of the Creative Commons Attribution License (http://creativecommons.org/licenses/by 14.0) and the Budapest Open Access Initiative (http://www.budapestopenaccessinitiative.org/rea d), which permit unrestricted use, distribution, and reproduction in any medium, provided the original work is properly credited.

\section{REFERENCES}

1. Sham TT, Chan CO, Wang YH, Yang JM, Mok DKW, Chan SW. A review on the traditional Chinese medicinal herbs and formulae with hypolipidemic effect. Bio Med

Trop J Pharm Res, December 2016; 15(12): 2546 
Res Int 2014; Article ID 925302. doi: 10.1155/2014/925302

2. Ford ES. Prevalence of the metabolic syndrome defined by the international diabetes federation among adults in the U.S. Diabetes Care 2005; 28 (11): 2745-2749.

3. Yun JW. Possible anti-obesity therapeutics from nature A review. Phytochem 2010; 71: 1625-1641.

4. Athyros VG, Tziomalos KA, Karagiannis, Mikhailidis DP. Dyslipidaemia of obesity, metabolic syndrome and type 2 diabetes mellitus: the case for residual risk reduction after statin treatment. Open Cardio Med J 2011; 5(24): 34-40.

5. Vermaak I, Viljoen AM, Hamman JH. Natural products in anti-obesity therapy. Nat Prod Rep 2011; 28: 14931533.

6. Xie W, Zhao Y, Du L. Emerging approaches of traditional Chinese medicine formulas for the treatment of hyperlipidemia. J Ethnopharmacol 2012; 140(2): 345367.

7. Wang $X$, Wang $D$, Li J, Ye C, Kubota K. Aroma characteristics of Cocoa tea (Camellia ptilophylla Chang). Biosci Biotech Biochem 2010; 74(5): 946-953.

8. Chang $H T$, Ye CX, Chang RM, Ma YD, Zhang P. A discovery of a new tea resource-cocoa tea tree containing theobromine from China. Acta Scientiarum Naturalium Universitatis Sunyatseni. 1988; 3: 131-133.

9. Bingfen $X$, Zongchao $L$, Qichao $P$. The anticancer effect and anti-DNA topoisomerase II effect of extracts of Camellia ptilophylla chang and Camellia sinesis. Chinese J Cancer Res 1994; 6(3): 184-190.

10. Kurihara H, Shibata H, Fukui Y. Evaluation of the hypolipemic property of Camellia sinensis var. ptilophylla on postprandial hypertriglyceridemia. J Agri Food Chem 2006; 54(14): 4977-4981.

11. Xia $D$, Wu X, Yang $Q$, Gong J, Zhang Y. Anti-obesity and hypolipidemic effects of functional formula containing Prumus mume in mice fed high fat diet. Afr J Biotechnol 2010; 9(16): 2463-2467.

12. European Commission. Directive 2010/63/EU on the protection of animals used for scientific purposes [Accessed on 2014 December 14]. Available from: http://ec.europa.eu/environment/chemicals/lab_animals/l egislation_en.htm.

13. Saad F, Haider A, Doros G, Long-term treatment of hypogonadal men with testosterone produces substantial and sustained weight loss. Obesity 2013; 21(10): 1975-1981.

14. Wing RR, Hill JO. Successful weight loss maintenance. Annu Rev Nutr 2001; 21: 323-341.
15. James WP, Caterson ID, Coutinho W, SCOUT Investigators. Effect of sibutramine on cardiovascular outcomes in overweight and obese subjects. $N$ Engl $J$ Med 2010; 363: 905-917.

16. Park JH, Lee MJ, Song MY, Bose S, Efficacy and safety of mixed oriental herbal medicines for treating human obesity: a systematic review of randomized clinical trials. J Med Food. 2012; 15(7): 589-597.

17. Grove KA, Lambert JD. Laboratory, epidemiological, and human intervention studies show that tea (Camellia sinensis) may be useful in the prevention of obesity. $J$ Nutrition 2010; 140(3): 446-453.

18. Basu A, Sanchez K, Leyva MJ. Green tea supplementation affects body weight, lipids, and lipid peroxidation in obese subjects with metabolic syndrome. J Am College Nutr. 2010; 29(1): 31-40.

19. Hooper L, Kroon PA, Rimm EB. Flavonoids, flavonoidrich foods, and cardiovascular risk: a meta-analysis of randomized controlled trials. Am J Clinical Nutrition 2008; 88(1): 38-50.

20. Bose M, Lambert JD, Ju J, Reuhl KR, Shapses SA, Yang CS. The major green tea polyphenol, (-)epigallocatechin-3-gallate, inhibits obesity, metabolic syndrome, and fatty liver disease in high-fat-fed mice. Journal of Nutrition. 2008; 138 (9): 1677-1683.

21. Wolfram S. Effects of green tea and EGCG on cardiovascular and metabolic health. J Am College Nutr 2007; 26(4): 373S-388S.

22. Xu X, Pan J, Zhou X. Amelioration of lipid profile and level of antioxidant activities by epigallocatechin-gallate in a rat model of atherogenesis. Heart Lung Circ. 2014; 23(12): 1194-1201.

23. Yang $X R$, Wae $T$, Ko YP, Wang $C H$, Koon CM, Siu WS, Gao S, Cheung DW, Lau CB, Ye CX, Leung PC. Effect of dietary cocoa tea (Camellia ptilophylla) supplementation on high-fat diet-induced obesity, hepatic steatosis, and hyperlipidemia in mice. Evid Based Complement Alternat Med 2013: article ID: 783860, doi: 10.1155/2013/783860.

24. Martin MA, Ramos S, Cordero-Herrero I, Bravo L, Goya L. Cocoa phenolic extract protects pancreatic beta cells against oxidative stress. Nutrients 2013; 5(8): 29552968.

25. Nicod N, Chiva-Blanch G, Giordano E, Davalos A, Parker $R S$, Visioli F. Green tea, cocoa, and red wine polyphenols moderately modulate intestinal inflammation and do not increase high-density lipoprotein (HDL) production. J Agric Food Chem. 2013; 62(10): 2228-2232. 